\title{
Scientific Tourism, Astronomical Tourism and Possible Solutions of Scientific Tourism
}

\author{
Robert Minasyan*and Naira Nalbandyan ${ }^{\dagger}$ \\ Armenian Institute of Tourism, the branch of Russian International Academy for Tourism
}

\begin{abstract}
The article discusses the ways and prospects of the development of scientific, in particular astronomical, tourism in Armenia.
\end{abstract}

Keywords: scientific tourism, types of tourism, astronomical tourism, regional tourism, resources of scientific tourism, scientific tourism in Armenia.

There is no sphere in the world that can develop without science. Armenia is considered to be a scientific country. Tourism is an industry, the existence of which brings income, permanent and temporary jobs. This is the reason why after a long discussion our government came to the conclusion that scientific tourism department should be established. The head of department became the director of Byurakan Observatory Areg Mikaelyan. The department with the scientists and students of Russian International Academy of Tourism participated in International scientific tours in Armenia and Kars Province in Historical Armenia for 3 years. The aim was to create for the first time a tourist product for the single country. We managed to create a new product for Russian market with the name of "Russian Trace" in the Armenian and Kars territory. It had a big resonance.
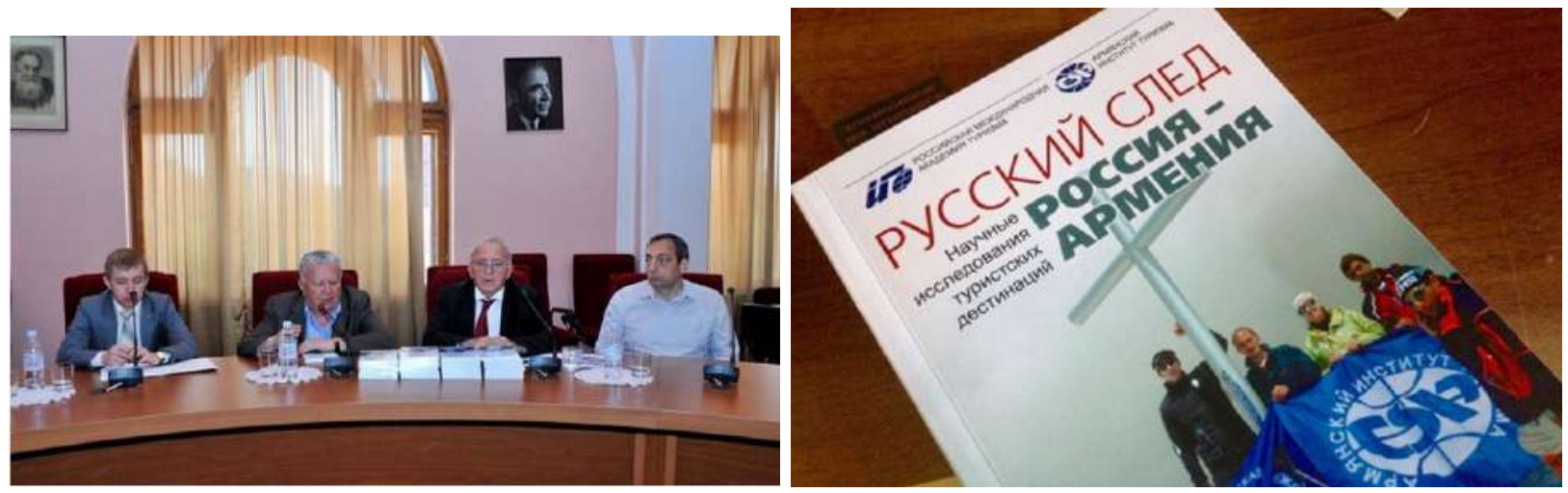

Figure 1.

Scientific tourism is a type of sustainable tourism according to a purpose and it has a direct connection with geographical, ethnic, archaeological, museum, cultural, astronomical, ethnographic types of tourism. People are very much interested in space, stars and other celestial bodies. In this regard astronomical tourism is the youngest but the most required one.

Development of astronomical tourism will promote the organization of regional tours, especially taking into consideration the possibilities of our neighbouring Iran's facilities of observatories.

*minasyanrobert@mail.ru, Corresponding author

${ }^{\dagger}$ nalbandyanait@gmail.com 

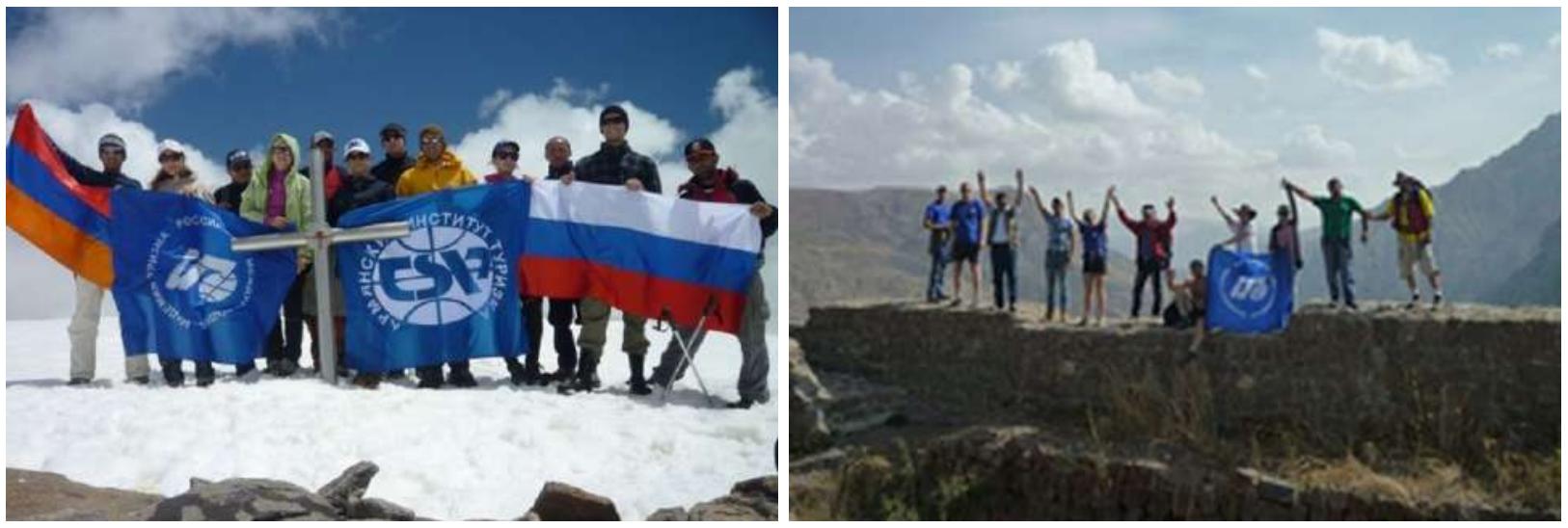

Figure 2.

In recent times tourism tends to innovate new types. From this perspective the development of science tourism in Armenia can be innovative and profitable. Scientific tourism expands and makes diverse a range of services as well as raises country's rating.

Nowadays specialists divide scientific tourism into 3 groups:

- Cognitive: Tourists get acquainted with nature, archaeological excavations, take part in stargazing during the travel.

- Experimental science tourism: In this case tourists take part in scientific works, for example in restoration of monuments.

- Individual scientific tourism: Tourists are scientists: astronomers, archaeologists, botanists, zoologists, architects, ethnographers, etc.

By definition of UNESCO scientific tourism is the discovery and recognition of scientific achievements, archaeological places and monuments. Scientific tourism is observed as a means of accessibility of scientific values as well as an effective means of preservation and recognition of heredity. Scientific tourism carries out scientific, exploratory activities in those areas which aren't considered to be a permanent residence for a tourist or areas that include at least one overnight stay without material benefit.

Scientific tourism is one of professional types of tourism and has the following features ${ }^{1}$ :

- It's a rare type of non-mass tourism

- It's a laborious process for the creation of the final tourism product

- It's a type of tourism which can make capital

- It has common features with different types of tourism (ecological, cognitive, business)

- It deals with individual's secondary demands

- With the use of non-traditional means of financing.

One of the most important factors in scientific tourism development is cultural and historical potential. Countries with non-developed economy but with rich natural and cultural potential are at the top of international tourism market.

The main types of scientific tourism according to visits are:

\footnotetext{
${ }^{1}$ Холодилина Ю.Е. Ресурсный потенциал региона как основа развития научного туризма. ВЕСТНИК ОГУ N 8 (144)/август 2012, ст. 169.
} 
- Astronomical: visits to observatories, observation at night, show programs of observatories, etc.

- Biological: study of flora and fauna

- Geo-climatic: study of unique climatic zones

- Ethnic: study of people's culture and lifestyle

- Geological: exploration of geological landscape and areas

- Archaeological study of ancient cultures and history of civilization

The purposes of scientific tourism are:

- Acquaintance with professional researches which are interesting from the scientific point of view

- Practical and educational visits of students (geological, historical, archaeological practice)

- Acquaintance with cultural and historical heritage and the history of scientific research of rare natural wealth.

The area where scientific tourism develops can be called the scientific tourism zone. The scientific tourism zone is the area where a unique object of great interest is situated.

The following demands are necessary for the effective activity of scientific tourism zones:

- Provision of resources (interesting objects for scientific tourists)

- Scientific platform (buildings and equipment for acquaintance and participation in scientific activity)

- Special equipped conditions for living and food

- Engineering building with electricity, heating and drainage system.

For scientific tourism development the following problems should be solved:

- Active collaboration for the unique cultural, historical and natural heritage preservation of the given place.

- The rise of people's pride and responsibility for their unique heritage.

- Tourism development program with the use of the unique local heritage.

Scientific places of visit, generally included in the travel packages projected by Armenian incoming tour operators, are the following:

- Erebuni Historical \& Archaeological Museum-Reserve

- Metsamor Historical-Archaeological Museum-Reserve

- Byurakan Astrophysical Observatory after V. Hambardzumyan of NAS of RA (National Academy of Sciences of the Republic of Armenia)

- Agarak Historical and cultural reserve

- Matenadaran Research of Ancient Manuscripts named after M. Mashtots

- Memorial Complex of Sardarapat Battle, National Museum of Armenian Ethnography and History of Liberal Struggle 


\section{- Aragat Cosmic Ray Research Station}

\section{- Zorats Karer (Carahunge)}

For the development of scientific tourism it's necessary to have the definite list of the resources of scientific interest which can become zones/centers of scientific tourism. It's important to mention the importance/description of the scientific resource and the development of scientific tourism in that area in the given list.

People are very much interested in space, stars and other celestial bodies. In this regard astronomical tourism is one of the newest and the most demanded types of tourism.

People travel to different parts of the world to see rare celestial phenomena such as solar and lunar eclipses, night sky views, explorations, etc.

Astronomical tourism is an amateur astronomers' group trips to ecologically clean areas accompanied by experienced scientists. Such trips are usually conducted in mountainous areas. This is explained by the fact that mountainous terrain is a suitable place to watch the celestial bodies as there isn't city dust and air pollution.

Astronomical tourism also includes visits to modern observatories where stargazings with telescopes are organized, as well as excursions to observatories remained from ancient times are conducted. Such excursions also have historical and cognitive function.

The interest of people to this type of tourism makes the management of observatories build suitable infrastructures to provide the visitors overnight stay and food. For example, in Chile a rest zone is created where a telescope is placed on the roof of every cottage.

It should be mentioned that the Byurakan observatory's management takes steps to develop astronomical tourism. There are designed tourist routes with interesting names ${ }^{2}$, developed lectures with a wide selection of topics, a souvenir trade point, a hotel, a canteen and other conditions to satisfy tourists' demands. But for developing scientific tourism, especially for expanding the possibilities of astronomical tourism, it can be more favorable to implement united regional astronomical tourism. There are many opportunities and wide interests. It's necessary to arrange united regional astrotouristic packages and bring them to the international market. If we regard the neighbouring Islamic Republic of Iran, we'll see that it has many attractive resources from this perspective, for example the Maragheh observatory which was established in $1259 \mathrm{CE}$ and was active for more than 100 years. It must be noted that Alenoush Terian was a famous Iranian-Armenian astronomer and physicist who was one of the founders of the first Iranian solar observatory.

Based on the given situation and problems it's important to solve the problems of the youth's integration and team work.

It's important to unify the activities of Armenian, Iranian and Russian young people who are engaged in the sphere of astronomy. It's necessary to join forces to solve tomorrow's problems. We mustn't wait today. It's urgent to unify ideas and abilities of young astronomers to solve common problems with the help of young astronomical tourism in favor of the participating countries.

It's recommended to make scientific travel packages with scientific opportunities of Georgia, Armenial, Iran, Turkey forming a regional travel package.

Professor Jafar Jafari in his book "Encyclopedia of Tourism" indicated that specialists of many branches such as historians, archaeologists, palaeontologists, philosophers, psychologists, culturologists, ethnographers, anthropologists, environmentalists, marketers, economists are interested in different types of tourism.

Each of these specialists studies tourism in his own way. Scientific tourism unites all these studies and makes tourism complete.

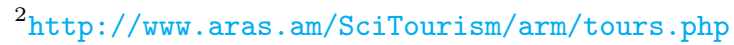




\section{Referencres}

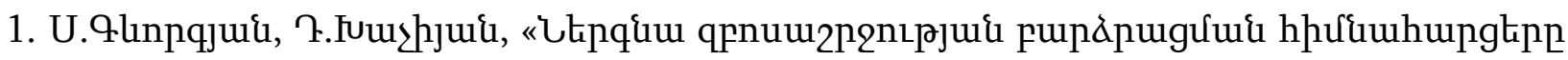

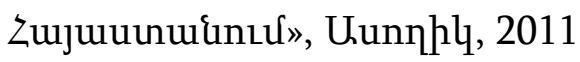

2. Холодилина Ю.Е. Ресурсный потенциал региона как основа развития научного туризма. ВЕСТНИК ОГУ №8 (144)/август` 2012, ст. 169.

3. Квартальновские научные чтения, Научный Альманах, г.Химки, 2014г

4. www.bao.am/arm1.htm ¿qUU. Fjnıpulquilp Uuunqunhunupuid

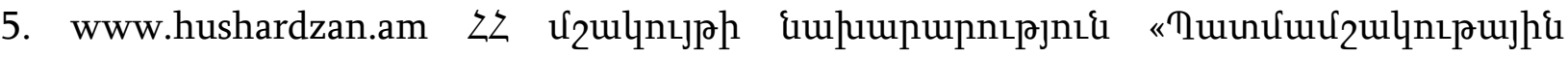

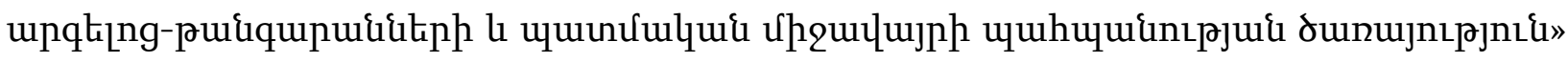
TกUบ

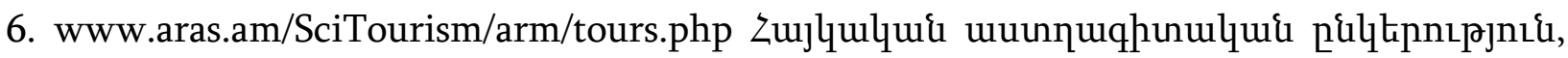

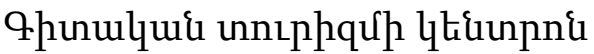

